\title{
Comparative Effect of Mastery Learning and Mind Mapping Approaches in Improving Secondary School Students' Learning Outcomes in Physics
}

\author{
Oluwatosin Omolara Blessing ${ }^{1}$, Bello Theodora Olufunke ${ }^{2}$ \\ ${ }^{1}$ Department of Science and Technology Education, Obafemi Awolowo University, Ile-Ife, Nigeria \\ ${ }^{2}$ Institute of Education, Obafemi Awolowo University, Ile-Ife, Nigeria
}

Email address:

bledora@yahoo.co.uk (T. O. Bello)

\section{To cite this article:}

Oluwatosin Omolara Blessing, Bello Theodora Olufunke. Comparative Effect of Mastery Learning and Mind Mapping Approaches in Improving Secondary School Students' Learning Outcomes in Physics. Science Journal of Education. Vol. 3, No. 4, 2015 , pp. $78-84$. doi: $10.11648 /$ j.sjedu.20150304.12

\begin{abstract}
This study investigated the effect of Mastery Learning Approach (MLA) and Mind Mapping Approach (MMA) in improving students' academic performance in Physics and also determined their effect in enhancing students' retention of Physics. These were with a view to ascertaining the best teaching method for improving students' learning outcomes in Physics. The study adopted the non-equivalent pre-test, post-test control group experimental design. Simple random sampling technique was used to select three co-educational secondary schools in Ikere Local Government Area of Ekiti State in Nigeria. The sample for the study was 74 senior secondary school one (SSS1) Physics students from the three selected secondary schools. Three intact classes were used for the study. The instrument used for data collection was "Physics Achievement and Retention Test" (PART). Data collected were analyzed using t-test and analysis of variance (ANOVA). The results showed that there was a significant effect of treatment on the academic performance of students taught with MLA, MMA and conventional method with students taught using MMA showing the best academic performance, followed by MLA and then Conventional. Also, no significant effect of treatment was found in the retention ability of students taught with MLA and MMA with students from both methods having nearly the same mean score. The study concludes that both MLA and MMA could improve students' learning outcomes in Physics; however, MMA could improve students' learning outcomes better. It therefore recommends that ministry of education should organize training for science teachers especially Physics teachers on how best they can adopt these innovative teaching strategies during instruction so that learners would be guided to learn meaningfully and be assisted to retain what is learnt in Physics.
\end{abstract}

Keywords: Mastery Learning, Mind Mapping, Retention, Learning Outcomes, Conventional, Teaching

\section{Introduction}

The importance of science to technological and economic development of a nation is internationally recognized. All over the world, nations are classified as developed, developing or underdeveloped based majorly on their scientific and technological strength. The development of any nation depends on the quality of scientific knowledge at the disposal of such nation. The knowledge of science is therefore a requirement in all countries and among all people globally in order to confront its challenges. Developed nations of the world are rated world powers because of their scientific knowledge which are applied to technological inventions. This can only be achieved by empowering the citizens with the knowledge of science and technology and engaging them in scientific and technological oriented careers. The National Policy on Education (NPE, 2004) stated clearly the need to train students to be able to make use of their environment in order to enhance the scientific and technological need of the society.

Physics is a fundamental science subject that is closely related to technology. It is a branch of physical science that explains the property of matter and energy and the relationship between them. Physics focuses on the general nature of the natural world. It has played a crucial role in the service of mankind and its principles are daily applied in our homes, lives and the discoveries made from these principles have been of great importance to human existence. The 
reliance on technology reveals the importance of Physics to mankind. Other disciplines such as agriculture, environmental, biological sciences as well as engineering courses use the laws of Physics to better understand their studies. Physics has many applications in medicine, transportation and communication technology. The fundamental discoveries in Physics are being used by medical communities to devise new techniques for diagnosing and treatment of a variety of illness. Modern means of transportation such as auto-mobiles, aircraft and other forms of technological innovations and advancement are all made possible through the application of some basic laws in Physics. Also in the entertainment industry, the principles of Physics are employed in the refinement of sound and colour mixing to create special effects in stage presentation. As one of the most active among the physical sciences, its principles formed the basis in information technology which has helped to reduce the world into a global village. Its importance in making the world worth living are too numerous to mention. All these lead to the development of social standard in both personal and professional life.

However, it is disheartening to know that despite the importance of Physics and its applications in various fields, the subject has been plagued by low enrolment, poor teaching method, limited number of professional trained Physics teachers and poor performance of students in the subject (Ogunniyi, 2009; Bello, 2012 and Owolabi \& Oginni, 2013). In many countries, there has been reduction in the number of students wishing to continue with Physics (Ho and Boo, 2007). Efforts have been made from various contributions of science educators and different educational boards towards making Physics simple and less difficult for students. Attempts have been made to find ways and means of improving students' academic performance in the subject. Different strategies and approaches have been suggested and empirical studies have been carried out on the effect of these strategies and approaches on the academic performance of students in Physics. Important factor in the determination of students' learning outcomes in Physics is the instructional technique adopted by the teachers. Physics teachers still frequently apply the old and conservative method of teaching, and Physics being a science subject is an activity oriented subject. The way it is taught is important in helping the students acquire basic scientific knowledge, better retention ability and skills to solving different problems in life. It is therefore important that the teacher employ teaching approaches (Mills, 1991) that will give students the opportunity to be actively involved in learning the subject. The different instructional strategies employed in teaching Physics such as cooperative teaching method (Bello, 2011) and concept mapping (Kibett and Kathuri, 2005) have not improved students' achievement in the subject to an appreciable extent. It is therefore pertinent to consider other teaching approaches such as mastery learning and mind mapping approaches which have been used to improve performance in other science subjects. Research is yet to ascertain how these approaches can impact on the learning of Physics thereby improving students' learning outcomes in the subject.

Mastery learning is an instructional strategy that is based on the principle that all students can learn a set of reasonable objectives when provided with appropriate instruction and sufficient time. It is a method in which students are given unlimited opportunities to demonstrate mastery of content taught. It involves breaking down the subject matter to be learnt into units of learning each with its own objectives. It gives students the opportunity to study a material unit after unit until they master it. Mastery learning uses differentiated and individualized instruction, progress monitoring, formative assessment, feedback, corrective procedures, and instructional alignment to minimize achievement gaps (Bloom, 1971) and focuses on how to improve the process of mastering content rather than changing it. Following a previous instruction, the teacher administers a brief formative assessment based on a unit learning goals. The assessment as a feedback informs the teacher about the student, which helps to identify what have been learnt and what needs to be learnt better. Students who have learnt the specified concepts continue their learning experiences while others who have not properly learnt the concept receive feedback paired with corrective activities different from the initial instruction and offer guidance and direction on how to remedy their learning challenges. These correctives can include varying activities, individualized instruction, and additional time to complete assignments. The challenge therefore becomes providing enough time and employing appropriate instructional strategies so that all students can attain the same level of learning. Obih \& Ekomaru (2011) stated that mastery learning is the mastery of a task, topic, or subject by every learner whereby the instruction is well related with the learner's characteristics and the learner is given the time required to learn the task, topic or subject and at the same time given the optimum quality of instruction.

Mind map which was first designed by Buzan in the 1970s is a technique based on students' understanding and interpretation. It is used for representing knowledge graphically and can help teachers to explain complex structures and relationships of concepts and to integrate graphically new knowledge with existing knowledge. It is an example of a non-linear approach to learning that encourages the learner to think radically and use only key words and images that are non-linearly linked together. In mind map, only essential words, clauses and phrases are used and the note becomes a combination of images with few words. According to Buzan \& Buzan (1996), a mind map is an expression of radiant thinking and is therefore a function of the human mind which provides a universal key to unlocking the potentials of the brain. He attributed the ready assimilation of graphical information to the way the brain organizes information. It is a visual learning method categorized under the broad family of graphic organizing tools which are constructed based on diagrams. Other examples of such graphic organizing tools include concept 
maps, tree diagrams, organization charts, and spider diagrams. According to Owolabi \& Oginni (2013), graphic organizers allow students to follow along with the lecture and build learners' understanding of each concept with the instructor. It also allows the instructor to informally assess students' knowledge as the lesson progresses.

Thomas (2007) defined a mind map as a powerful graphic technique which harnesses the full range of cortical skills such as word, image, number, logic, rhythm, colour and spatial awareness in a single, powerful manner. It therefore gives the freedom to roam the infinite expanses of the brain. Holzman (2004) in Daniel and David (2011) stated that thinking maps allow students to express their thoughts and ideas non-linguistically and instructors actually see the graphic representation of students' thought process. According to Zollman \& Robert (2008), learners can only think critically about contents of subject matter to be learnt if they understand the basic terms to be learnt and the relationship between associated concepts. In this wise, learning a particular subject matter becomes a mental building process. Thus, mind map enable learners to actively construct a conceptual framework to which new ideas and knowledge are added, related and refined thereby improving on their learning capability and strategy. Mind map can stimulate learners' interest by making learning an active process (Pan, 2010). Therefore, when used as part of instructional approach is potent at increasing students' achievement score, knowledge and retention (Adodo, 2013) and also has the potentials to enable students engage in reflective thinking (Madu \& Metu, 2012).

These two approaches recognize individual differences in learners and encourage them to create their own knowledge at their own pace. This study will compare the influence of the two teaching approaches in order to determine which of the approaches is most effective in enhancing students' retention ability and improving their academic performance in Physics.

\subsection{Objectives of the Study}

Despite the importance of Physics to nation's scientific and technological development, students' learning outcomes in the subject had been very low. Over the years, concerted efforts had been made to improve the teaching of the subject. The different instructional strategies employed in teaching the subject had yielded little improvement. Mastery Learning Approach (MLA) and Mind Mapping Approach (MMA) have been used to improve learning outcomes in other science subjects with relative success. It is on this note that this study aims at investigating the effect of MLA and MMA on the learning outcomes of secondary school students in Physics. Therefore, the specific objectives of the study are to:

i. examine the effect of Mastery Learning Approach (MLA) and Mind Mapping Approach (MMA) in improving students' academic performance in Physics;

ii. compare the effect of these approaches in enhancing students' retention of Physics.

\subsection{Research Hypotheses}

In order to establish the stated objectives, research hypotheses needed to be formulated and tested based on data collected and analysed. Therefore, the following research hypotheses were generated to guide the study.

i. There is no significant difference in the effect of MLA, MMA and conventional method on students' academic performance in Physics.

ii. There is no significant difference in the effect of MLA and MMA on students' retention of Physics.

\section{Research Design}

The study adopted the non-equivalent pre-test, post-test, control group design to verify the relative effectiveness of MLA and MMA on students' learning outcomes in Physics. The non-equivalent pre-test, post-test, control group design is a type of quasi-experimental design. Quasi-experimental design is similar to experimental design except for the lack of randomization into groups. This research design is used because secondary schools exists in intact classes and the randomization of students into groups for experimental purpose is simply not allowed to avoid the disintegration of the classes. The pre-test post-test suggests that measurements are taken before and after the introduction of the intervention. The pre-test helps in assessing the differences between the experimental and the control groups and to establish a baseline for the effect of the treatment.

The design is represented schematically as follows:

$\mathrm{O}_{1} \mathrm{X}_{1} \mathrm{O}_{4} \quad$ - Experimental group A

$\mathrm{O}_{2} \mathrm{X}_{2} \mathrm{O}_{5} \quad$ - Experimental group $\mathrm{B}$

$\mathrm{O}_{3} \mathrm{X}_{3} \mathrm{O}_{6} \quad$ - Control group

where $\mathrm{O}_{1}, \mathrm{O}_{2}$, and $\mathrm{O}_{3}$ are the pre-test scores of the experimental groups $\mathrm{A}$ and $\mathrm{B}$ and the control group respectively. Also, $\mathrm{O}_{4}, \mathrm{O}_{5}$, and $\mathrm{O}_{6}$ are their respective posttest scores.

$$
\begin{aligned}
& \mathrm{X}_{1}=\text { Mastery Learning Approach (MLA) } \\
& \mathrm{X}_{2}=\text { Mind Mapping Approach (MMA) } \\
& \mathrm{X}_{3}=\text { Conventional teaching approach (control) }
\end{aligned}
$$

\subsection{Population, Sample and Sampling Technique}

The population for the study consisted of all senior secondary school Physics students in Ekiti State, Nigeria. The sample consisted of 74 Physics students in their intact classes in three selected secondary schools in Ikere Local Government Area of Ekiti State. Simple random sampling technique was used in the selection of the three schools. The three selected schools were randomly assigned into experimental groups A and B, and the control group C. The schools were located in a semi-urban area in the southwestern region of Nigeria. Majority of the people in this area are into trading and farming while few percentage of the them are civil servants. The justification for using this area is based on the fact that it has a mixture of literate and nonliterate citizens whose children are the samples used in the selected schools. 


\subsection{Research Instrument}

The instrument used for data collection was a Physics Achievement and Retention Test (PART), which consisted of twenty structured multiple choice questions. The PART was used as a pre-test to ascertain equivalent ability of the students as well as a post-test after treatment to determine the effect of the intervention on their academic performances. After two weeks, the students were re-tested to determine their retention of the concepts taught. The instrument was given to two experts in education and students' Physics teachers to establish the face validity of the instruments. Their corrections were followed in selecting the items included in the instrument. Field testing was carried out by administering the instruments on some students from an intact class of a co-educational secondary school different from the selected schools used for the study. Test retest method was used to generate 2 set of scores for the students. The scores were subjected to correlation in other to determine the reliability of the instrument. The reliability coefficient of the instrument was found to be 0.78 .

\subsection{Procedure for Data Collection}

This was done in phases. In the first phase, the researcher visited the chosen schools to seek for permission in using the students as well as some facilities in the schools. This was followed by the administration of the PART as a pretest to the students in the two experimental groups and the control group to ascertain the equivalence in ability of the students. In the second phase, the treatments were introduced to the experimental groups. Students in experimental group A were taught using the MLA, those in experimental group B were taught using the MMA while the control group $\mathrm{C}$ were taught using the conventional approach. Two topics (Gravitational Field and Electric Field) were taught concurrently in all the three schools using the appropriate treatment in each school for a period of four weeks. Then the PART was administered to the three groups as post-test. In the third phase, the PART was re-structured and administered to the three groups after two weeks of the post-test to serve as a retention test.

The pre-test, post-test and retention test were scored to generate quantitative data which were analyzed using Analysis of Covariance (ANCOVA) and the independent samples t-test. ANCOVA was used to analyze differences in the three means of the pre-test and post-test scores and to determine whether the differences are significant. t-test was used when dealing with two means (when analyzing the retention test scores between the two groups) because of its superior power to detect differences between two means. Significance level of 0.05 was used to test the null hypotheses.

The students that were used for the study have prior knowledge in Physics and in topics related to those that were used in the study. The researcher ascertained that schools with students that have same prior knowledge were used, this was done by visiting the schools and interacting with the Physics teacher in each school and by the use of the pre-test which was administered to the students. Also, the researcher carried out the teaching in these schools so as to have all the students exposed to the same Physics teacher but with different instructional strategies. The teacher is a degree holder in Physics education and has undergone training in pedagogy of teaching in her subject area. Her skill in this area is very good. This was exhibited in the lesson note and instructional materials that were used by the teacher for each group based on the strategy.

\section{Results}

The results of the analysis of the pre-test scores in the PART for the experimental groups and the control group were analyzed and the results are presented in table 1.

Table 1. Analysis of Variance (ANOVA) of the Pre-test Scores.

\begin{tabular}{llllll}
\hline Source of Variation & $\begin{array}{l}\text { Sum of } \\
\text { Squares }\end{array}$ & df & $\begin{array}{l}\text { Mean } \\
\text { Square }\end{array}$ & F & Sig. \\
\hline Between Groups & 10.542 & 2 & 5.271 & 2.60 & 0.226 \\
Within Groups & 246.052 & 71 & 3.466 & & \\
Total & 256.595 & 73 & & & \\
\hline
\end{tabular}

$\mathrm{p}>0.05$

Table 1 shows that there is no significant difference between the means of the three groups $(F=2.60, p>0.05)$. This means that the $F$ value is not significant at $p>0.05$ level and between groups mean square is not significantly greater than within groups mean square. This result shows that there were no significant differences in the pre-test scores across the three groups; it was therefore ascertained that the three groups started with equivalent means which reveals the equivalent ability of the students in the three groups prior to the introduction of the treatments.

Hypothesis One: There is no significant difference in the effect of MLA, MMA and conventional method on students' academic performance in Physics.

To test this hypothesis, the post-test scores of the students in the two experimental groups and the control group were compared and analyzed using ANCOVA and Post-Hoc test at 0.05 level of significance. The results are presented in tables 2, 3 and 4 .

Table 2. Descriptive Statistics of Students'Scores.

\begin{tabular}{llll}
\hline Group & Mean & Std. Deviation & N \\
\hline MLA & 6.5357 & 1.95282 & 28 \\
MMA & 8.4000 & 1.50238 & 15 \\
Control & 5.3548 & 1.72334 & 31 \\
Total & 6.4189 & 2.08719 & 74 \\
\hline
\end{tabular}

Table 2 shows the mean scores of the students in the MLA, MMA and the control group as 6.5357, 8.4000 and 5.3548 respectively. This indicates that the performance of the students exposed to MMA is the best among the three groups. 
Table 3. ANCOVA of the performance of students exposed to MLA, MMA and the conventional method.

\begin{tabular}{lllllll}
\hline Source & Type III Sum of Squares & df & Mean Square & F & Sig. & Partial Eta Squared \\
\hline Corrected Model & $104.958^{\mathrm{a}}$ & 3 & 34.986 & 11.495 & 0.000 & 0.330 \\
Intercept & 438.313 & 1 & 438.313 & 144.009 & 0.000 & 0.673 \\
Group & 102.920 & 2 & 51.460 & $16.907^{*}$ & 0.000 & 0.326 \\
Pre-test & 10.606 & 1 & 10.606 & 3.485 & 0.066 & 0.047 \\
Error & 213.055 & 70 & 3.044 & & & \\
Total & 3367.000 & 74 & & & & \\
Corrected Total & 318.014 & 73 & & & & \\
\hline
\end{tabular}

*sig. at $\mathrm{p}<0.05$

Table 3 shows the ANCOVA of the students' scores in the three groups $(\mathrm{F}=16.907, \mathrm{p}<0.05)$. The result suggests a statistical significant effect of the approaches on students' academic performance in Physics. The Post-Hoc test presented in table 4 indicates the direction of the experimental effect.

Table 4. Pair-wise Comparisons of Students'Scores.

\begin{tabular}{lllllll}
\hline \multirow{2}{*}{ (I) Group } & (J) Group & \multicolumn{2}{c}{ Mean Difference (I-J) } & Std. Error & Sig. & \multicolumn{2}{c}{ 95\% Confidence Interval for Difference } \\
\cline { 5 - 7 } & & & & & Lower Bound & Upper Bound \\
\hline \multirow{2}{*}{ MLA } & MMA & $-2.050^{*}$ & 0.567 & 0.002 & -3.441 & -0.659 \\
& Control & $1.191^{*}$ & 0.455 & 0.032 & 0.075 & 2.307 \\
\multirow{2}{*}{ MMA } & MLA & $2.050^{*}$ & 0.567 & 0.002 & 0.659 & 3.441 \\
& Control & $3.241^{*}$ & 0.559 & 0.000 & 1.871 & 4.612 \\
\multirow{2}{*}{ Control } & MLA & $-1.191^{*}$ & 0.455 & 0.032 & -2.307 & -0.075 \\
& MMA & $-3.241^{*}$ & 0.559 & 0.000 & -4.612 & -1.871 \\
\hline
\end{tabular}

*. The mean difference is significant at the .05 level.

b. Adjustment for multiple comparisons

The results in table 4 shows that the mean difference between the MMA group and MLA group (2.050) was lower the mean difference between the MMA and control group (3.241). This point to the difference in effect of three approaches in improving students' performance in Physics with MMA showing the highest effect followed by the MLA and then the conventional method. Since the MMA improves students' academic performance in Physics than MLA and the conventional method, the null hypothesis is rejected. Therefore, the alternative hypothesis is hereby established that there is significant difference in the effect of MLA, MMA and conventional method on students' academic performance in Physics.

Hypothesis Two: There is no significant difference in the effect of MLA and MMA on students' retention of Physics.

To test this hypothesis, the retention test scores of the students taught using MLA was compared with those taught with MMA using the independent samples t-test. The result is presented in table 5 .

Table 5. T-test analysis of the retention test score of students taught Physics under MLA and MMA.

\begin{tabular}{lllllll}
\hline Test & Group & N & Mean & Std. Deviation & T & df \\
\hline \multirow{2}{*}{ Retention } & MMA & 15 & 6.6000 & 1.29835 & 0.263 & 41 \\
& MLA & 28 & 6.4643 & 1.75293 & & \\
\hline
\end{tabular}

Table 5 is the result of the t-test for independent samples carried out to test whether there is a significant difference in retention ability of the students exposed to the two experimental groups. Although the mean score of the students in the MMA group (6.60) is higher than that of the MLA (6.46), the difference is not significant. $(t=0.263, p>$ $0.05)$, this implies that there is no overall effect of the treatments. Therefore the null hypothesis is accepted.

\section{Discussion}

The findings of the study revealed that there was no significant difference in the performance of Physics students before they were taught Physics using MLA, MMA and the conventional approach. This suggests that the three groups were quite homogenous at the start of the study. It implies that students used for the study have relatively equal background knowledge of Physics.

The result of hypothesis one which states that there is no significant difference in the effect of MLA, MMA and the conventional method of teaching on students' academic performance in Physics showed that the three teaching approaches used have effect on the academic performance of the students in their groups as the post-test mean scores in each group are higher than the respective pre-test mean scores. This is an indication that the treatments given improved the performance of the students. The result also 
showed that the students in the MMA group performed better than those in the MLA group and then the control group. This is in agreement with Farrand, Hussan \& Hennessy (2002) who opined that MMA improved the performance of medical students, and Rooda (1994) that MMA is an effective tool for improving the performance of student in nursing. It has been argued that conventional teaching method is content centered in which teachers remain more active, more cognitive and less effective (Singh, 2004). According to Rao (2001), the method is concerned with the recall of factual knowledge and largely ignores higher levels of cognitive outcomes, the teacher seeks to transfer thoughts, and meanings to the learners leaving little room for student-initiated questions, independent thought or interaction between students (Yore, 2001), also it is detrimental to students' learning process (Zoller, 2000). The use of interactive techniques and strategies help the student to become more engaged in learning and retain more information, thus giving them satisfaction (Steinert \& Snell, 1999). It is therefore necessary to provide interesting classes for students so that teachers can have positive feedback from them (Alarcon, 2005).

Furthermore, the result of hypothesis two which states that there is no significant difference in the effect of the approaches on students' retention of Physics showed no significant difference in the retention of students taught using the two approaches. The result implies that the two approaches equally improved students' retention of Physics.

\section{Conclusion and Recommendations}

The study had been able to show that MMA is more effective in improving the academic performance of students in Physics when compared with MLA and conventional teaching method. This implies that MMA has the capacity to help students associate ideas, think creatively, and make connections that might not be achievable in the conventional note taking approach. Although, the two approaches used in this study do not differ in the ways they enhance the retention ability of Physics concepts by learners. This implies that the two could improve on the learners' retention ability in the same proportion.

It therefore entails that MMA would be one of the most effective learning strategy that could be employed by teachers to overcome many of the problems encountered in teaching and learning of Physics.. As most students experience difficulty in learning Physics. In similar manner, MLA could also be used to effectively teach and learn Physics but where the facilities needed for MMA are available; it should be utilized to be able to obtain maximum output by learners.

Based on the findings of this study and the conclusion reached, the following recommendations are made:

- Science educators and researchers should gear their efforts towards understanding the characteristic, strength and weaknesses of the individual learners so as to help in designing the appropriate instructional programmes to meet their needs.
- Following the findings of this study that MMA significantly improves learning, it is recommended that Physics teachers should adopt the strategy and other participatory strategies during instruction so that learners could be guided to learn meaningfully.

- Students should be encouraged to use mind mapping in note taking as it helps to hold information in a format that the mind find easy to recall and quick to review. This will help the students in remembering the acquired information.

- Seminars, workshops and conferences should be organized by the ministry of education for Physics teachers to educate them on how to implement mind mapping strategy in school.

\section{References}

[1] Adodo, S. O. (2013). Effect of mind mapping as a selfregulated learning strategy on students' achievement in basic science and technology. Mediterranean Journal of Social Sciences, 4 (6). 163-172.

[2] Alarcon, M. (2005). Physics without tears. A World of Science, $3(1), 1-7$.

[3] Bello, T. O. (2011). Effect of group instructional strategy on students' performance in selected Physics concepts. The African Symposium: An on-line Journal of African Educational Research Network, 11(1), 71-79.

[4] Bello, T. O. (2012). Effect of Availability and Utilization of Physics Laboratory Equipment on Students' Academic Achievement in Senior Secondary Schools Physics. World Journal of Education. Vol. 2 (5), 1-7.

[5] Bassey, M. (2003). School science for tomorrow's citizen. New York: Pergamon Press.

[6] Bloom, B. S. (1971). Mastery learning. New York: Holt, Rinehart \& Winston.

[7] Buzan, T. \& Buzan, B. (1996). The mind map book: How to use radiant thinking to maximize your brain's untapped potential. New York: Plume.

[8] Daniel, L. \& David C. (2011). Mind the map: How thinking maps affect student achievement. Networks online Journal, 13 (2), $1-7$

[9] Farrand, P., Hussan, F., \& Hennessy, E. (2002). The efficacy of the mind map study technique. Medical Education, 36 (5), 426-431.

[10] Federal Republic of Nigeria (2004). National Policy on Education. Lagos: NERDC Press.

[11] Ho, F.E. \& Boo, H.K. (2007). Cooperative learning: Exploring its effectiveness in Physics classroom. Asia Pacific Forum on Science Learning and teaching, 8 (2).

[12] Kibett, J.K. \& Kathuri, N.J. (2005). Effects of projected-based learning on students' performance in secondary school Agriculture. Zimbabwe Journal of Educational Research, 17 (1), 30-38. 
[13] Madu, B. C. \& Metu, I. C. (2012).Effect of mind map as a note-taking approach on students' achievements in Economics. Journal of Emerging Trends in Economics and Management Sciences, 3 (3), 247-251.

[14] Mills, H.R. (1991). Teaching and Training. A handbook for Instructors $\left({ }^{\text {rd }}\right.$ Ed.). London: Macmillan Publisher.

[15] Obih, S. O. \&Ekomaru, C. I. (2011).Innovative teaching strategies emerging myths and realities in teaching and tearning.International Association for Teaching and Learning, 271-277.

[16] Ogunniyi, M. B. (2009). Science, technology and Mathematics.International Journal of Science Education, 18 (3), 267-284.

[17] Owolabi, O. T. \& Oginni O. I. (2013). Assessing the relative effectiveness of three teaching methods in the measurement of students' performance in Physics. International Journals of Material, Methods and Technologies, 1 (8), 116-125.

[18] Pan Z. (2010). Promoting e-learners' self-monitoring with mind map. Proceedings of the third international symposium on computer science and computational technology.

[19] Rao, D. (2001). Science education in developing countries. New Delhi: Discovery Publishing House.
[20] Rooda, L. A. (1994). Effects of mind mapping on student achievement in a nursing research course. Nurse Education, $19,25-27$.

[21] Singh, Y.K. (2004). Teaching of social studies. New Delhi: APH Publishing Corporation.

[22] Steinert, Y. \& Snell, L. S. (1999).Interactive lecturing strategies for increasing participation in large group presentations. Medical Teacher. 21 (1), 37-42.

[23] Thomas, H. S. (2007). Today's topics on creativity engineering system division. Massachusetts: Institute of Technology.

[24] Yore, L. D. (2001). What is meant by constructivist science teaching and will the science education community stay the course for meaningful reform? Electronic Journal of Science Education, 5 (4).

[25] Zoller, U. (2000). Teaching tomorrow's college science courses - Are we getting it right? Journal of College Science Teaching, 29 (6), 409-414.

[26] Zollman, D. \& Robert, G. (2008).Teaching and learning physics with interactive Video. Lincoln, USA, University of Nebraska, Lincoln Press. 